\title{
Natural Killer Cell Lymphoblastic Leukemia/Lymphoma
}

National Cancer Institute

\section{Source}

National Cancer Institute. Natural Killer Cell Lymphoblastic Leukemia/Lymphoma. NCI

Thesaurus. Code C82217.

A provisional entity describing precursor lymphoid neoplasms that express CD56 and

immature T-cell markers, lack B-lymphoid and myeloid markers, and have the immunoglobulin and T-cell receptor genes in the germline configuration. 